\title{
Resistance to Erosive Wear of Epoxy-Polyurethane Coating Modified With Nanofillers
}

\author{
Danuta Kotnarowska $^{1}$, Michał Przerwa ${ }^{2} \&$ Tadeusz Szumiata ${ }^{3}$ \\ ${ }^{1}$ Department of Mechanical Engineering, University of Technology and Humanities, Radom, Poland \\ ${ }^{2} \mathrm{PhD}$ Student at University of Technology and Humanities, Radom, Poland \\ ${ }^{3}$ Department of Physics, University of Technology and Humanities, Radom, Poland \\ Correspondence: Danuta Kotnarowska, Department of Mechanical Engineering, University of Technology and \\ Humanities, al. Chrobrego 45, Radom 26-600, Poland. Tel: 48-48-361-7670. E-mail: d.kotnarowska@uthrad.pl
}

Received: September 25, 2013

Accepted: October 16, 2013 Online Published: February 27, 2014

doi:10.5539/jmsr.v3n2p52

URL: http://dx.doi.org/10.5539/jmsr.v3n2p52

\begin{abstract}
The paper presents results of investigation on the erosive wear kinetics of epoxy-polyurethane coatings modified with alumina or silica nanoparticles, aged climatically for three years. Destruction of coating surface layers due to natural weathering caused a decrease of their erosive wear resistance. Modification of the composition of polyurethane (surface) layer with nanofiller caused the remarkable increase of erosion resistance. Epoxy-polyurethane coatings with nanosilica modified surface layer, showed the highest erosive wear resistance of all investigated coatings.
\end{abstract}

Keywords: epoxy-polyurethane coating, erosive wear resistance, nanofillers

\section{Introduction}

A polymer protective coating during its service life in natural conditions is exposed to the action of climatic and environmental factors, that contribute to various types of wear, including erosive wear. The coatings erosive wear process occurs when hard particles (hail, dust, sand, stones, soil lumps etc.) impact their surface. Therefore, erosion is the dominating wear process of polymer protective coatings of agricultural, constructional and mining machines and occurs as a result of erosive particles impacts typical for a given environment (Kotnarowska, 1999a, 2006).

An action of operational factors has a crucial influence on polymer coating surface state. An intensive chemical and physical destruction of superficial layers occurs as the result of aggressive media adsorption on coating surface and due to the action of ultraviolet radiation,. Ultraviolet radiation is the dominating factor that causes destruction of polymer coatings used in natural climatic conditions (Kotnarowska, 2006). This contributes to the decrease of resistance to erosive wear of epoxy coatings, first of all due to a significant increase of binding resin brittleness and also to an increase of the coating surface roughness. Also cracks (including silver cracks) generated inside the superficial layers of coating reduce its resistance to erosive wear (Al-Turaif, 2013; Darowicki, Szociński, Schaefer, \& Mills, 2011).

Polymeric coatings modified with nanofillers may show better functional properties (higher scratch and abrasion resistance, higher hardness, lower water permeability) than coatings containing microfillers. The effect depends on many factors like, among others, the following: chemical nature of nanofillers, their concentration and level of dispersion in the coating, as well as interaction between filler particles and polymer matrix (Perera, 2004; Chen, Zhou, Chen, \& Wu, 2005; Douce, Boilot, Biteau, Scodellaro, \& Jimenez, 2004; Zhou, Wu, Sun, \& Shen, 2002).

Nowadays, works are carried out concerning size of filler particles as well as their contribution in the polymer matrix influence on the protective properties (Kotnarowska, 2008; Leder, Ladwig, Valter, Frahn, \& Meyer, 2002; Wang, Bai, Liu, Wu, \& Wong, 2002) and operational durability of polymer coatings (Wang et al., 2011). Usually, the smaller filler particles the bigger their effect on coating properties (Fu, Feng, Lauke, \& Mai, 2008; Moloney \& Kausch, 1987; Zhou, Lu, Jiang, \& Li, 2005; Kotnarowska, 2009).

A modification of the paint composition with nanofiller may lead to improvement of polymer coatings resistance 
to scratch, abrasion and to erosive particle impacts. Most frequently metal nanoparticles (aluminium, silver, copper) or metal compounds (zinc oxide, aluminium oxide, titanium dioxide, iron oxides) are used to paints modification. Calcium carbonates, modified layered silicates and carbon nanotubes are used for this purpose as well (Amerio et al., 2008; Bautista, Gonzalez, Gilabert, Ibanez, \& Sanz, 2011; Al-Turaif, 2010; Huang, Li, \& Yuan, 2001; Oner, Meral, \& Nergis, 2013).

Nanofillers have larger specific surface area compared to the conventional fillers which increases their adhesion strength with polymer matrix (Fu et al., 2008; Stojanović et al., 2013). Improved mechanical properties of coatings containing nanofillers result from better conditions for stress propagation inside the coating material. Usually, the stronger physico-chemical bonding between filler particles and polymer matrix is, the easier stress can be transferred through the particle-matrix interfaces and dissipated (Pilotek \& Tabellion, 2005).

To prevent agglomeration of nanofillers, various methods are applied in the paint formulation process, such as: mechanical or preferably ultrasonic mixing and chemical modification of nanofillers surface. Chemical modification of surfaces of most inorganic nanoparticles (e.g. $\mathrm{SiO}_{2}, \mathrm{Al}_{2} \mathrm{O}_{3}$ or $\mathrm{ZnO}_{2}$ ) influences their hydrophilic character promoting physical bonding with the paint material as well as facilitating their distribution in the polymer matrix.

The erosive wear process of polymer coatings is still not sufficiently recognized, because coating material loss depends on many interrelated factors (Asmatulu, Mahmud, Hille, \& Misak, 2011; Kotnarowska, 1999b, 2010b; Kotnarowska, Przerwa, \& Wojtyniak, 2011). Therefore, studies on the erosive wear kinetics of polymer coatings should consider the degree of their destruction under the influence of such environmental factors like: acid rains, ultraviolet radiation, mechanical stresses (Barkoula, 2002; Patnaik, Satapathy, Chand, Barkoula, \& Biswas, 2010; Kotnarowska, 1997, 2010a).

\section{Experimental}

\subsection{Preparation of Test Samples}

Two types of three-layered epoxy-polyurethane coatings were investigated. They were applied by air-spraying on a steel substrate in the form of $160 \times 80 \times 2 \mathrm{~mm}$ plates made of S235JR steel. First two epoxy layers (primer and interlayer) were deposited. Then the surface layer was made of unmodified polyurethane paint (type A) or nanofiller modified polyurethane paint (type B) as it is shown in Figure 1.
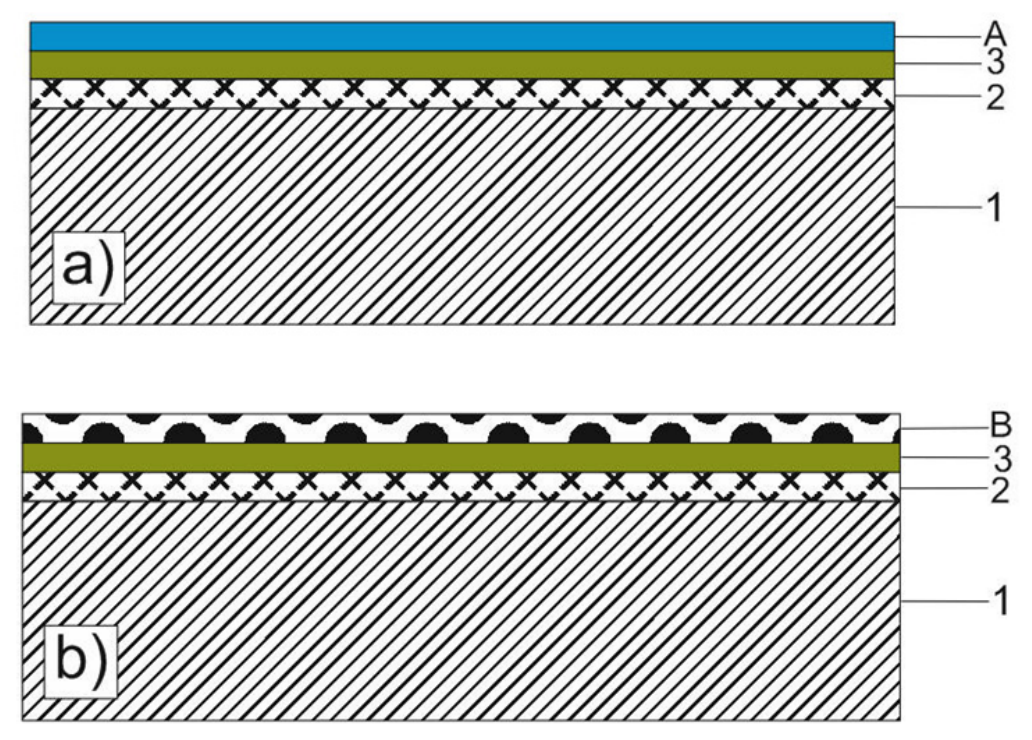

Figures 1 (a \& b). Scheme of the investigated epoxy-polyurethane coatings: a) unmodified coating, b) modified coating, where: 1 - steel substrate, 2 - primer layer (epoxy), 3 - interlayer (epoxy), A - unmodified polyurethane surface layer, B - nanofiller modified polyurethane surface layer (not to scale)

The steel plates surface were specially prepared by grit blasting (in a special tumbler) with the use of small ceramic bars. Prior to coating application the plates were degreased with ethyl alcohol. 
In order to improve the erosive wear resistance (also scratch resistance) the polyurethane paint was modified with alumina nanoparticles $\mathrm{Al}_{2} \mathrm{O}_{3}$ (of $20 \mathrm{~nm}$ grain size) or silica nanoparticles (of $12 \mathrm{~nm}$ grain size). The nanofiller content in the paint was $3.5 \%$ (by weight). Surfaces of nanofillers particles were chemically modified by manufacturers. The alumina nanoparticles were modified with methoxypropyl acetate using polysiloxane as the carrier whereas hydrophobic silica nanoparticles were modified with dimethyldichlorosilane. To prevent agglomeration of nanofillers paints were mechanically stirred for 18 hours. Moreover, applied nanofillers slow down a sedimentation of other particles (pigments, stabilizers) in coating material increasing its anticorrosive characteristics without a negative influence on decorative properties.

Directly after the paint spraying the samples of epoxy-polyurethane coatings were acclimatized for 10 days at the temperature of $20{ }^{\circ} \mathrm{C}$ and the relative humidity of $65 \pm 5 \%$. Then the samples were placed on racks situated in a climatic station on the grounds of Institute of Machines and Vehicles Maintenance in Radom and subjected to ageing in natural climatic factors for three years. The average thickness of three-layer epoxy-polyurethane coatings was $190 \mu \mathrm{m}$ while the thickness of the polyurethane surface layer was $70 \mu \mathrm{m}$.

\subsection{Erosive Wear Evaluation Methodology}

The resistance to erosive wear of the coatings aged for the period of three years was evaluated using the testing device recommended by Polish Standard PN-76/C-81516 (Figure 2).

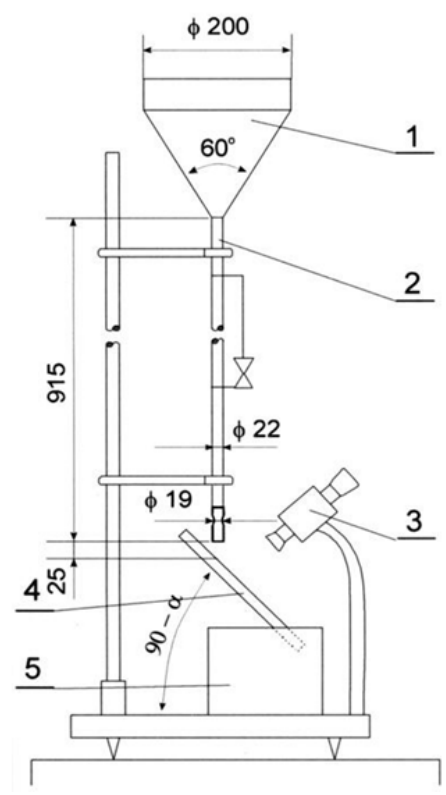

Figure 2. Apparatus for erosive wear of polymer coatings testing, where: 1 - container for erosive material, 2 pipe transporting erosive material, 3 - optical microscope, 4 - tilting holder for fixing metallic test specimen with examined coating, 5 - container collecting erosive material after the test

Particles of granulated alundum 99A (according to the Polish Standard PN-76/M-59111) of grain number 30 (according to PN-ISO 8486-2) were used as the abrasive material (Figure 3). Alundum grains were of the size $0.60 \div 0.71 \mathrm{~mm}$. The main constituent of erosive material was aluminium trioxide (minimum 99\%). Other constituents were: silicon dioxide, iron trioxide, calcium oxide and sodium oxide. The erosive particles were poured through the pipe in which they were falling freely from the height of $0.915 \mathrm{~m}$ onto the sample surface. The sample with tested epoxy-polyurethane coating was tilted by $45^{\circ}$. 


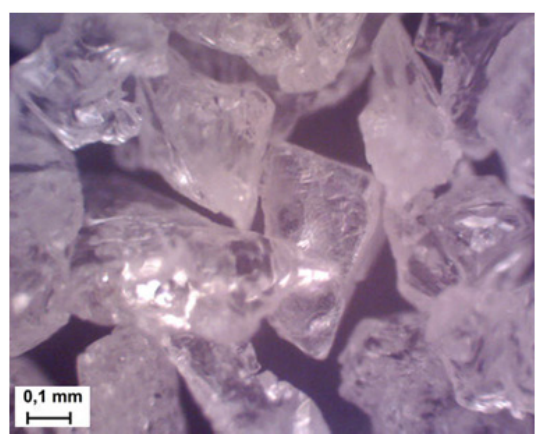

Figure 3. Morphology of alundum particles

The initial mass of one charge of alundum was $3.5 \mathrm{~kg}$. When the first signs of coating wear up to the substrate material appeared, the mass of one alundum charge was reduced to $0.5 \mathrm{~kg}$. The pouring of abrasive material was continued until the area of exposed substrate achieved the shape of ellipse of minor diameter equal $d=3.6 \pm 0.1 \mathrm{~mm}$. The tests were carried out at the temperature of $20 \pm 2{ }^{\circ} \mathrm{C}$ and the relative humidity of $65 \pm 5 \%$.

The resistance to erosive wear of epoxy-polyurethane coatings was evaluated applying the criterion $S$ according to Equation (1). It expresses a proportion of the total mass $M$ of erosive particles which erode the coating (generating normative coating wear) to the coating thickness $\mathrm{G}(1)$ :

$$
S=\frac{M}{G},
$$

where: $S$ - erosive wear resistance, $[\mathrm{kg} / \mu \mathrm{m}] ; M$ - mass of erosive particles, $[\mathrm{kg}] ; G$ - average coating thickness, $[\mu \mathrm{m}]$.

\section{Results and Discussion}

The action of climatic factors caused cracking of polyurethane superficial layers of epoxy-polyurethane coatings and increasing of their porosity. Whereas adhesion loss between particles of fillers and polyurethane material caused their chipping from the coating superficial layer contributing to the increase of its roughness. It resulted in decrease of the resistance to erosive wear of testing epoxy-polyurethane coatings.

In order to describe a time evolution of the resistance to erosive wear of epoxy and polyurethane coatings, a phenomenological expression $S(t)$ consisting of exponential and Gaussian terms was introduced (2). First of them describes a continuous (long-term) process of coating destruction and its nature represents progressive propagation of silver cracks. The second component of Equation (2), which is the Gaussian function, models a periodic process of coating resistance to erosive wear increase as the result of coatings hardening and roughness decrease during the climatic ageing. The explicit form of $S(t)$ expression is following:

$$
S(t)=A_{e} e^{-\frac{t}{T_{e}}}+A_{G} e^{-\frac{\left(t-T_{G}\right)^{2}}{2 \Delta T_{G}^{2}}},
$$

where: $A_{\mathrm{e}}$ - is an amplitude of exponential process, $T_{\mathrm{e}}-$ a time constant of exponential process, $A_{\mathrm{G}}-$ amplitude of Gaussian-type evolution, $T_{\mathrm{G}}$ - its characteristic time, and $\Delta T_{\mathrm{G}}-$ a time spread of Gaussian changes.

The time characteristics of the erosive wear resistance of epoxy-polyurethane coatings are presented in Figure 4. 


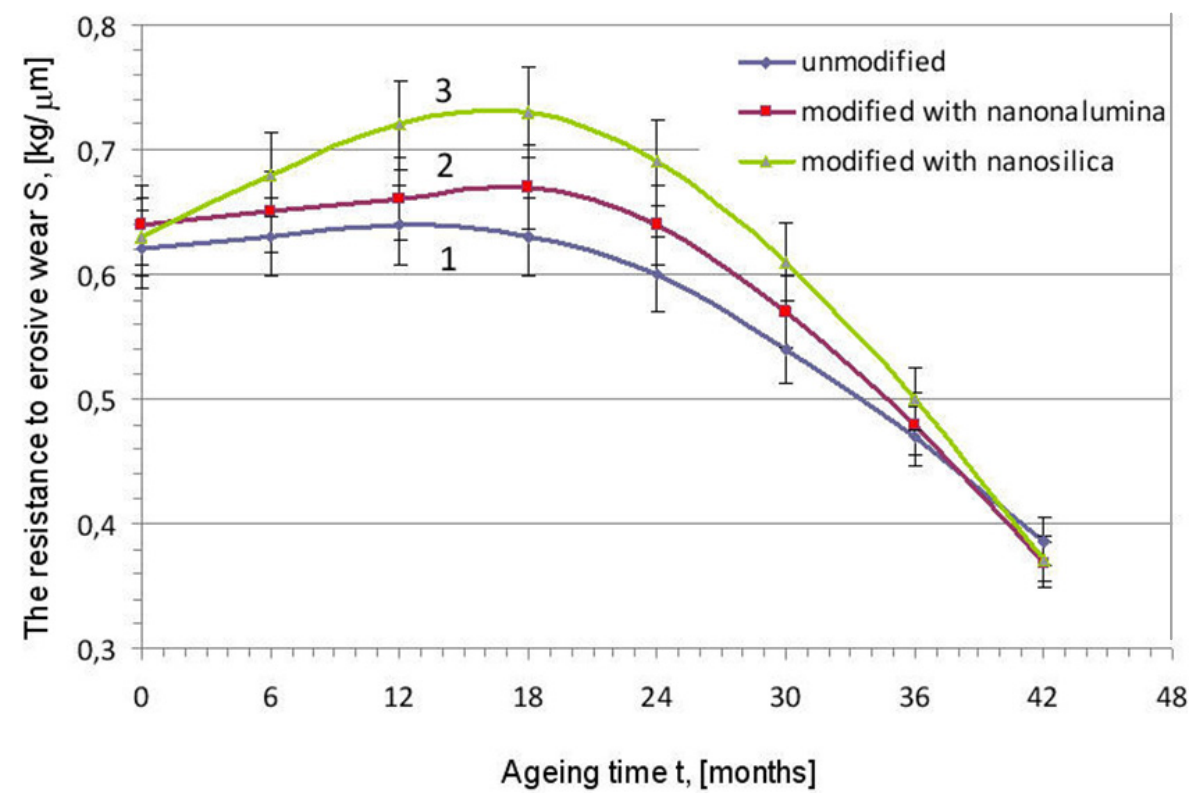

Figure 4. The resistance to erosive wear of epoxy-polyurethane coatings as a function of time, where: 1 unmodified epoxy -polyurethane coating, 2 - epoxy-polyurethane coating with nanoalumina modified surface layer, 3 - epoxy-polyurethane coating with nanosilica modified surface layer

\section{Conclusions}

(1) Modification of polyurethane superficial layer of epoxy-polyurethane coating with nanofiller (silica as well as alumina) caused erosive resistance increase of epoxy-polyurethane coatings aged climatically, especially during the period from 6 to 30 months. The epoxy-polyurethane coating with superficial layer modified with silica nanoparticles exhibited the highest erosive resistance

(2) The increase of coating erosive resistance was caused by higher hardness of modified coatings as well as by lower roughness of their surface layers in comparison with unmodified coatings. Moreover, nanofillers filled pores existing inside the coatings and effectively suppressed development of cracks arising in the coating as the result of ageing.

\section{References}

Al-Turaif, H. A. (2010). Effect of nano $\mathrm{TiO}_{2}$ particle size on mechanical properties of cured epoxy resin. Progress in Organic Coatings, 69, 241-246. http://dx.doi.org/10.1016/j.porgcoat.2010.05.011

Al-Turaif, H. A. (2013). Surface morphology and chemistry of epoxy-based coatings after exposure to ultraviolet radiation. Progress in Organic Coatings, 76, 677-681. http://dx.doi.org/10.1016/j.porgcoat.2012.12.010

Amerio, E., Fabbri, P., Malucelli, G., Messori, M., Sangermano, M., \& Taurino, R. (2008). Scratch resistance of nano-silica reinforced acrylic coatings. Progress in Organic Coatings, 62, 129-133. http://dx.doi.org/10.1016/j.porgcoat.2007.10.003

Asmatulu, R., Mahmud, G. A., Hille, C., \& Misak, H. E. (2011). Effects of UV degradation on surface hydrophobicity, crack, and thickness of MWCNT-based nanocomposite coatings. Progress in Organic Coatings, 72, 553-561. http://dx.doi.org/10.1016/j.porgcoat.2011.06.015

Barkoula, N. M. (2002). Review processes and influencing parameters of the solid particle erosion of polymers and their composites. Journal of Materials Science, 37, 3870-3820. http://dx.doi.org/10.1023/A:1019633515481

Bautista, Y., Gonzalez, J., Gilabert, J., Ibanez, M. J., \& Sanz, V. (2011). Correlation between the wear resistance, and the scratch resistance, for nanocomposite coatings. Progress in Organic Coatings, 70, 178-185. http://dx.doi.org/10.1016/j.porgcoat.2010.09.022

Chen, Y., Zhou, S., Chen, G., \& Wu, L. (2005). Preparation and characterization of polyester/silica

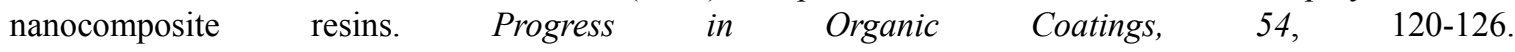


http://dx.doi.org/10.1016/j.porgcoat.2004.03.013

Darowicki, K., Szociński, M., Schaefer, K., \& Mills, D. J. (2011). Investigation of morphological and electrical properties of the PMMA coating upon exposure to UV irradiation based on AFM studies. Progress in Organic Coatings, 71, 65-71. http://dx.doi.org/10.1016/j.porgcoat.2010.12.012

Douce, J., Boilot, J. P., Biteau, J., Scodellaro, L., \& Jimenez, A. (2004). Effect of filler size and surface condition of nano-sized silica particles in polysiloxane coatings. Thin Solid Films, 466, 114-122. http://dx.doi.org/10.1016/j.tsf.2004.03.024

Fu, S. Y., Feng, X. Q., Lauke, B., \& Mai, Y. W. (2008). Effects of particle size, particle matrix/interface adhesion and particle loading on mechanical properties. Composites: Part B, 39, 933-961. http://dx.doi.org/10.1016/j.compositesb.2008.01.002

Huang, Z., Li, Z. Z., \& Yuan, X. (2001). The effect of reinforcing particles on the erosive wear behavior of particles reinforced silicone matrix composite coating. Wear, 249, 1046-1050. http://dx.doi.org/10.1016/S0043-1648(01)00807-9

Kotnarowska, D. (1997). Kinetics of wear of epoxide coating modified with glass microspheres and exposed to the impact of alundum particles. Progress in Organic Coatings, 31, 325-330. http://dx.doi.org/10.1016/S0300-9440(97)00090-8

Kotnarowska, D. (1999a). Influence of ageing on mechanical properties of epoxide coating. Journal of Corrosion Science and Engineering, 2, 1-10. Retrieved from http://www.jcse.org/volume2/paper28/v2p28.php

Kotnarowska, D. (1999b). Influence of ultraviolet radiation and aggressive media on epoxy coating degradation. Progress in Organic Coatings, 37, 149-159. http://dx.doi.org/10.1016/S0300-9440(99)00070-3

Kotnarowska, D. (2006). Influence of ultraviolet radiation on erosive resistance of modified epoxy coatings. Solid State Phenomena, 113, 585-588. http://dx.doi.org/10.4028/www.scientific.net/SSP.113.583

Kotnarowska, D. (2008). Influence of mechanical factors on surface state of acrylic coatings with nanofillers. Materials Science, $\quad 14, \quad 337-340 . \quad$ Retrieved from http://internet.ktu.lt/lt/mokslas/zurnalai/medz/pdf/medz0-95/13\%20Polymers...(pp.337-340).pdf

Kotnarowska, D. (2009). Effect of nanofillers on wear resistance of polymer coatings. Solid State Phenomena, 144, 285-290. http://dx.doi.org/10.4028/www.scientific.net/SSP.144.285

Kotnarowska, D. (2010a). Effect of erosive particle velocity on the Intensity of polymeric coating wear. Solid State Phenomena, 165, 91-95. http://dx.doi.org/10.4028/www.scientific.net/SSP.165.91

Kotnarowska, D. (2010b). Epoxy coating destruction as a result of sulphuric acid aqueous solution action. Progress in Organic Coatings, 67, 324-328. http://dx.doi.org/10.1016/j.porgcoat.2009.10.026

Kotnarowska, D., Przerwa, M., \& Wojtyniak, M. (2011). Effect of epoxy and polyurethane coating modification with nanofillers on their resistance to erosive wear. Journal of Vibroengineering, 13, 870-876. Retrieved from http://jve.lt/Vibro/JVE-2011-13-4/JVE-2011-13-4-704-D_Kotnarowska.pdf.pdf

Leder, G., Ladwig, T., Valter, V., Frahn, S., \& Meyer, J. (2002). New effects of fumed silica in modern coatings. Progress in Organic Coatings, 45, 139-144. http://dx.doi.org/10.1016/S0300-9440(02)00049-8

Moloney, A. C., \& Kausch, H. H. (1987). Review parameters determining the strength and toughness of particulate filled epoxide resins. Journal of Material Science, 22, 381-393. http://dx.doi.org/10.1007/BF01160743

Oner, I., Meral, A., \& Nergis, A. (2013). Preparation of nanocoatings in the presence of precipitated $\mathrm{CaCO}_{3}$ fillers by UV-curing. Progress in Organic Coatings, 76, 950-954. http://dx.doi.org/10.1016/j.porgcoat.2012.10.014

Patnaik, A., Satapathy, A., Chand, N., Barkoula, N. M., \& Biswas, S. (2010). Solid particle erosion wear characteristics of fiber and particulate filled polymer composites: A review. Wear, 268, 249-263. http://dx.doi.org/10.1016/j.wear.2009.07.021

Perera, D. Y. (2004). Effect of pigmentation on organic coating characteristics. Review. Progress in Organic Coatings, 50, 247-262. http://dx.doi.org/10.1016/j.porgcoat.2004.03.002

Pilotek, S., \& Tabellion, F. (2005). Nanoparticles in coatings. Tailoring properties to applications. European Coatings Journal, 4, 170-172. 
Stojanović, D. B., Brajović, L., Orlović, A., Dramlić, D., Radmilović, V., Uskoković, P. S., \& Aleksić, R. (2013). Transparent PMMA/silica nanocomposites containing silica nanoparticles coating under supercritical conditions. Progress in Organic Coatings, 76, 626-631. http://dx.doi.org/10.1016/j.porgcoat.2012.12.002

Wang, D. L., Watson, S. S., Sung, L. P., Tseng, I. H., Bouis, C. J., \& Fernando, R. (2011). Effect of $\mathrm{TiO}_{2}$ pigment type on the UV degradation of filled coatings. Journal of Coatings Technology and Research, 8, 19-33. http://dx.doi.org/10.1007/s11998-009-9216-y

Wang, H., Bai, Y., Liu, S., Wu, J., \& Wong, C. P. (2002). Combined effects of silica filler and its interface in epoxy resin. Acta Materialia, 50, 4369-4377. http://dx.doi.org/10.1016/S1359-6454(02)00275-6

Zhou, R., Lu, D. H., Jiang, Y. H., \& Li, Q. N. (2005). Mechanical properties and erosion wear resistance of polyurethane matrix composites. Wear, 259, 676-683. http://dx.doi.org/10.1016/j.wear.2005.02.118

Zhou, S., Wu, L., Sun, J., \& Shen, W. (2002). The change of the properties of acrylic-based polyurethane via addition of nano-silica. Progress in Organic Coatings, 45, 33-42. http://dx.doi.org/10.1016/S0300-9440(02)00085-1

\section{Copyrights}

Copyright for this article is retained by the author(s), with first publication rights granted to the journal.

This is an open-access article distributed under the terms and conditions of the Creative Commons Attribution license (http://creativecommons.org/licenses/by/3.0/). 